\title{
A ESCOLA, O PERTENCIMENTO E A GEOGRAFIA COMO DISCIPLINA ESCOLAR
}

\author{
Augusto Monteiro OZORIO ${ }^{\mathrm{i}}$ \\ Antonio CHIZZOTTI ${ }^{\mathrm{ii}}$
}

\begin{abstract}
RESUMO
Este artigo analisa o papel da instituição escolar na sociedade contemporânea, bem como o propósito da disciplina Geografia nos currículos escolares. Nele, é discutida a própria escola como instituição pública, regida pelo Estado, bem como o currículo escolar, não apenas como forma de controle, mas também como política pública a serviço da criação da noção de pertencimento à ordem mundial condizente com o modo urbano industrial. Trata-se de uma pesquisa bibliográfica sobre a institucionalização da escola e do currículo escolar que, por meio do método materialista dialético, alterna entre escalas de análise a fim de vislumbrar o papel do ensino da Geografia na criação e consolidação do nacionalismo como forma de consolidação da noção de pertencimento ao mundo contemporâneo, marcado pela onipresença dos Estados Nacionais. Por fim, ele apresenta uma contribuição para a discussão curricular acerca do significado e importância dos propósitos do ensino dessa disciplina no ambiente escolar, em especial no que se refere ao fortalecimento do debate sobre as possibilidades no processo de implementação da recente Base Nacional Comum Curricular (BNCC) brasileira.
\end{abstract}

PALAVRAS-CHAVE: Currículo; Ensino de Geografia; Currículo Escolar.

\section{SCHOOL, BELONGING AND GEOGRAPHY AS SCHOOL DISCIPLINE}

\begin{abstract}
This article analyzes the role of the school institution in the contemporary society and the purpose of geograpy as a discipline in the school curriculum. On the article, the school itself is discussed as a public institution - governed by the state - as well as the school curriculum, not only as a way of control, but also as a public policy in the service of creating an idea of belonging to a consistent world-wide order aligned with the industrial urban mode. This is a bibliographic research about the school institutionalization its curriculum, which, through the dialectical materialist method, alternates among scales of analysis in order to envision the role of the geography discipline - and its teaching in creating and reinforcing the nationalism as a way to consolidate the idea of belonging to the contemporary world, which is marked by the omnipresence of national states. Finally, it presents a contribution to the curricular discussion about the meaning and the importance of the purposes of teaching this discipline in the school environment, especially regarding the strengthening of the debate about possibilities in the process of implementing the recently approved Common National Curricular Base (brazilian BNCC).
\end{abstract}

KEYWORDS: Curriculum; Geography teaching; School curriculum.

\footnotetext{
${ }^{\text {i }}$ Estágio de Pós-Doutorado em Educação na FE-USP, em andamento. Professor do EBTT - Instituto Federal de Ciência e Tecnologia de São Paulo (IFSP). E-mail: monteiro.augusto@ifsp.edu.br - ORCID iD: https://orcid.org/0000-0003-3812-3690.

ii Pós-doutorado no Institut National de Recherche Pédagogigue de Paris. Professor do Programa de PósGraduação em Educação da PUC-SP. Professor titular aposentado da Universidade Federal de Uberlândia. Email: anchizo@uol.com.br - ORCID iD: https://orcid.org/0000-0002-2752-2330.
} 


\title{
LA ESCUELA, PERTENENCIA Y LA GEOGRAFÍA COMO DISCIPLINA ESCOLAR
}

\begin{abstract}
RESUMEN
Este artículo analiza el papel de la institución escolar en la sociedad contemporánea, así como el propósito de la disciplina de Geografía en los currículos escolares. Se discute la propia escuela como institución pública, regida por el Estado, así como el currículo escolar, no solo como una forma de control, sino también como una política pública al servicio de crear la noción de pertenencia al orden mundial consistente con el modo industrial urbano. Se trata de una investigación bibliográfica sobre la institucionalización de la escuela y el currículo escolar que, a través del método materialista dialéctico, alterna escalas de análisis para vislumbrar el papel de la enseñanza de la Geografía en la creación y consolidación del nacionalismo como forma de consolidación desde la noción de pertenencia al mundo contemporáneo, marcado por la omnipresencia de los Estados Nacionales. Finalmente, presenta un aporte a la discusión curricular sobre el significado e importancia de los propósitos de la enseñanza de esta disciplina en el ámbito escolar, especialmente en lo que respecta a fortalecer el debate sobre las posibilidades en el proceso de implementación del reciente Base Nacional Común Curricular (BNCC) Brasileña.
\end{abstract}

PALABRAS CLAVE: Currículo; Enseñanza de la Geografía; Currículum escolar.

\section{INTRODUÇÃO: A INSTITUCIONALIZAÇÃO DA ESCOLA E A CONSTRUÇÃO DA NOÇÃO DE PERTENCIMENTO À SOCIEDADE URBANO-INDUSTRIAL}

O debate sobre o currículo e os propósitos da instituição escolar requerem o esforço de aproximá-los ao contexto dos valores e crenças da sociedade que os criou e os institucionalizou como uma política pública de caráter estatal ou, numa perspectiva complementar, buscar compreender o significado da presença da escola como parte da institucionalização do Estado Nacional como dimensão estruturante da política burguesa a partir do século XVIII.

Esse artigo parte inicialmente do recorte espácio-temporal que se restringe ao continente europeu, em meio ao contexto das mudanças políticas, econômicas e sociais que se caracterizaram a partir das revoluções burguesas delineadas no século XVII, mas, principalmente, ao longo do século XVIII.

Trata-se, portanto, nesse primeiro momento, do surgimento da instituição escolar republicana no continente europeu, decorrente das transformações que conduziram uma sociedade estruturalmente agrária a uma sociedade fundamentalmente urbano-industrial, da institucionalização da escola e do currículo como política pública no século XIX.

Para o entendimento dessas transformações que, em suas contradições, produziram a Escola de ontem e que diz respeito à Escola de hoje, é necessário aprofundar a compreensão 
dessa sociedade que vislumbrou na Escola a possibilidade de transmitir para as gerações seguintes seu legado cultural e, assim, construir suas noções de pertencimento.

Para Chizzotti e Ponce (2012, p. 26), há uma intrínseca relação entre a noção de currículo como forma de controle e o assentamento das relações capitalistas na organização da sociedade em Estados Nacionais:

Na Modernidade, concomitante à chegada de novas organizações: econômica - que assentou os pilares capitalistas - e política - que se deu pela secularização dos poderes por meio da organização do Estado Nacional, desenvolveram-se, não linearmente, as primeiras noções de currículo como processo ensino-aprendizagem mais exposto ao controle, com sequência, completude e, posteriormente, certificação. O que virá a chamar-se currículo escolar ganha expressão com o desenvolvimento dos Estados Nacionais. Historicamente, o processo de escolarização, entendido como institucionalizado, sequenciado e passível de avaliação e controle, teria se iniciado nesse amplo momento.

Destacam-se dois aspectos relevantes sobre o papel da instituição escolar na construção da noção de pertencimento à sociedade urbano-industrial, de caráter estatal nacionalista: primeiro, a relação entre o currículo e o assentamento das relações econômicas que mais tarde se caracterizariam como capitalistas já na organização da sociedade burguesa europeia em Estados Nacionais.

O segundo aspecto diz respeito à própria ideia de currículo como controle apresentada por Hamilton (1992), uma vez que será a partir dessas novas relações econômicas (capitalistas) e políticas (Estados Nacionais) que os termos série, seriação e formas de agrupamentos de alunos e a seriação dos conteúdos escolares vão se consolidar ${ }^{1}$, para mais adiante caracterizar a ideia de certificação reconhecida pelo próprio Estado.

Nesse mesmo artigo, Hamilton (1992) apresenta que, durante os séculos XII e XIII, estudantes (adultos) vinham, de diferentes partes da Europa, estudar na universidade de Bolonha para aprender, de um grupo inovador de juristas (teóricos legais), entre outras coisas, os problemas enfrentados pelos proprietários de terra que queriam transformar sua "posse" (ou administração) numa relação de propriedade absoluta, o que corrobora a colocação acerca da associação entre o papel da escola e a construção da noção de pertencimento a um novo modelo de sociedade que mais adiante se caracterizaria na forma capitalista.

Essa foi uma primeira demanda para o posterior surgimento da instituição escolar 
como forma de inserção dos indivíduos na sociedade que viria a ser urbano-industrial.

Do ponto de vista do surgimento da instituição escolar e do currículo, tais mudanças na sociedade fizeram com que o papel dessa instituição e do currículo fosse sendo ressignificado, ganhando novos contornos para cada contexto até o momento atual.

Diante das demandas de uma sociedade que se urbanizava, na medida em que o processo de industrialização se intensificava, atribui-se à instituição escolar a responsabilidade de criar as condições que permitissem o pertencimento e a solidariedade dos cidadãos no território do estado. A instituição escolar foi incumbida de trazer a responsabilidade de criar as condições que propiciassem o pertencimento nessa nova situação.

Tal questão coloca o currículo no centro desse debate, na medida em que é a caracterização do currículo, definido na correlação de forças pelos sujeitos, que vai sistematizar quais conhecimentos serão necessários para que a instituição escolar possa cumprir esse propósito de formar os cidadãos.

Assim, pode-se vislumbrar uma leitura sobre como o processo de construção de uma nova ideia de mundo e sociedade serviu de base para a passagem do mundo feudal para o mundo urbano-industrial apoiada na ideia de cidadania, colocando a escola e o currículo no centro dessa política de formação do estado nacional.

Que importância a Geografia poderia ter para que lhe fosse atribuído o status de disciplina escolar e, assim, compor o currículo? Que papel lhe caberia na constituição dessa noção de pertencimento a essa nova estrutura político-econômica e social?

Nos itens a seguir, procura-se explicitar tais proposições, mas, antes, é importante trazer para esse debate alguns aspectos referentes ao papel da escola em difundir a escrita, para construção dessa noção de pertencimento à sociedade urbano-industrial.

\section{A SUBSTITUIÇÃO DA ORALIDADE PELA ESCRITA COMO FUNDAMENTO DA SOCIEDADE URBANO-INDUSTRIAL}

É preciso considerar que existem aspectos muito relevantes quando se apresenta uma sociedade a partir de seu caráter estruturalmente rural, pois isso implica mais que uma relação dos indivíduos e da coletividade com um modo de produção. Significa, igualmente, uma relação abstrata e subjetiva de entendimento de mundo. 
Naturalmente, uma modificação nas relações de produção, do modo artesanal para o modo industrial e, portanto, de uma estrutura agrária para uma estrutura urbana industrial, vai provocar mudanças radicais no entendimento que as pessoas têm do mundo, em seus diversos desdobramentos.

Thompson (1998), na obra Costumes em comum, coloca que a revolução industrial e a revolução demográfica foram o pano de fundo da maior transformação da história, chamando a atenção para a passagem do mundo pré-industrial para o mundo moderno, por meio da mudança das necessidades e do papel das tradições e dos costumes baseados na tradição oral.

Antes, o autor esclarece: "Nos séculos precedentes, o termo costume foi empregado para denotar boa parte do que hoje está implicado na palavra 'cultura'. O Costume era 'a segunda natureza' do homem" (THOMPSON, 1998, p. 14). Além disso, adverte que se deve evitar um reducionismo evolucionista dessa transição de uma sociedade agrária e rural para a sociedade urbana e industrial. Nesse sentido, o autor apresenta muitos exemplos de contradições que envolveram esse processo, demonstrando que, embora seja possível encontrar um fio condutor que nos guie na compreensão desse fenômeno, na prática, esse foi um caminho construído com fundamento nas condições daquele momento.

Os zelosos propagandistas dos cercamentos reservam o papel de vilões e de inimigos do "progresso" aos colonos teimosos, aos pequenos proprietários, aos posseiros [...]. Mas as classes sociais podem desempenhar papéis duplos [...]. Pois esses vilões podem ser vistos como atores que desempenharam um papel revolucionário no crescimento da "protoindustrialização" ou da "economia de colonato". A sua pobreza e a marginalidade de seu acesso à terra os estimulavam a realizar esforços prodigiosos para desenvolver ofícios rurais e empregos secundários industriais nas margens das terras comunais. [...] fazer sapatos, tecidos, móveis ou pregos e, em geral, exercendo toda e qualquer habilidade protoindustrial possível (THOMPSON, 1998, p. 142).

Nessa obra, o autor realiza uma minuciosa discussão acerca da substituição da oralidade, como base dos costumes e tradições que organizavam (social, política e econômica) a sociedade inglesa até o início do século XVIII, chamando a atenção para o cercamento das terras na Inglaterra como base material para o início do processo da revolução industrial naquele país - processo profundamente marcado por situações contraditórias e complexas, mas que tinha, no pano de fundo, o surgimento de uma nova noção de propriedade. 
Vale considerar que essa discussão já havia sido precedida, em sua apresentação, pela linguagem cartográfica, à medida que, a partir das grandes navegações, a produção cartográfica ganhou absoluta relevância, respondendo aos anseios dessa nova noção de propriedade territorial que vinha sendo forjada.

Antes, os mapas "T-O", produzidos no contexto feudal, sacramentavam as leituras de mundo pautadas pela visão religiosa e serviam de base à consolidação de ideologias e leituras de mundo para o pertencimento àquela sociedade (SANTOS, 2002).

Tratando-se a cartografia como mais uma forma de linguagem, a demanda pela difusão da escrita torna-se mais abrangente e, nesse caso, mais pertinente aos objetivos desse debate.

Para Hobsbawm (2014), é preciso considerar que, até 1789, ano que marca o início da revolução francesa e que significou a ascensão da burguesia na França ao controle do Estado, o mundo era essencialmente rural e seria impossível tentar entendê-lo sem levar em conta esse dado.

Ademais, segundo Hobsbawm (2014), países como a Rússia e regiões como a Escandinávia ou os Balcãs, onde as cidades não tiveram um desenvolvimento tão acentuado, cerca de $90 \%$ a $97 \%$ da população era rural. Também ressalta que, exceto em algumas áreas comerciais e industriais bastante desenvolvidas, seria muito difícil encontrar um grande Estado no continente europeu, onde ao menos quatro de cada cinco habitantes não fossem camponeses. Diz ainda: "na maioria dos países da Europa ocidental, a ordem feudal implícita na maneira de pensar estava ainda muito viva politicamente, embora fosse cada vez mais obsoleta em termos econômicos" (HOBSBAWM, 2014, p. 41).

Havia, nesse contexto, uma contradição posta entre o costume, que era transmitido pela oralidade como fundamento do direito consuetudinário, e a noção de propriedade privada, que começara a se constituir nas relações de produção a partir do acesso à terra como meio de produção.

Thompson (1998) aponta que "o costume é local, Lex loci” e, para a noção de propriedade que estava em construção, essa prática da oralidade, das leis consuetudinárias, não era compatível, uma vez que a noção de propriedade privada dependeria do Estado para se sustentar e não poderia ser local, e sim estatal. "Na interface da lei com a prática agrária, 
encontramos o costume. O próprio costume é a interface, pois podemos considerá-lo como práxis e igualmente como lei. A sua fonte é a práxis" (THOMPSON, 1998, p. 86).

A noção de pertencimento pelos costumes e de direito pela oralidade precisava ser substituída por um direito que fosse o mesmo para todos e sob o controle de quem dominava o próprio Estado. Há de mudar a escala, se quiser modificar as relações sociais na direção do capitalismo fabril. Dessa maneira, as leis deveriam passar a ser escritas para que fossem válidas.

Surge, a partir desses referenciais, uma demanda econômica e política de uma sociedade fundada no direito escrito e, com ela, a demanda por uma sociedade que tivesse o domínio da linguagem escrita - nesse momento, pelo menos para uma parcela da população.

Assim, ressalta-se o papel que a linguagem, na forma escrita, cumpriu na construção ideológica de pertencimento a esse novo mundo, com base nessa recente noção de propriedade.

Trata-se de uma passagem muito significativa para a compreensão dos valores e crenças que fundamentaram a sociedade moderna até os dias de hoje e que vão recair sobre o significado social da instituição escolar, em face do papel que se tem atualmente para a noção de pertencimento.

Luria (2012), em "Diferenças culturais de pensamento", descreve todo o processo de uma pesquisa, na extinta União Soviética, na qual são apresentadas, como resultado, formas distintas de apreensão do mundo entre as pessoas não alfabetizadas e as que passaram pelo processo de alfabetização.

Nessa pesquisa, as diferentes formas não significam que uma seja melhor que outra, apenas que cada grupo, alfabetizado e não alfabetizado, desenvolveu noções que são próprias do mundo ao qual pertence. Apresenta-se também, especialmente, que há distinções no modo da cognição, dadas pelo contexto social de uma sociedade urbana para rural.

Temos, essencialmente, a mudança de uma sociedade agrária, com a oralidade como base das relações sociais, para uma sociedade urbano-industrial, com a palavra escrita, como fundamento e materialização dessas novas relações sociais e econômicas.

A palavra escrita pôde assumir a forma de representação de um valor, ou seja, do domínio de uma propriedade no modelo reconhecido pelo Estado. Isso significaria dizer que 
dominar esse novo modo de representação da propriedade passaria a ser um pressuposto para pertencer a essa nova sociedade.

Até então, no mundo essencialmente rural, onde não havia a noção de propriedade privada da terra, a Igreja exercia um importante papel nas relações de poder, e o domínio da escrita ficava restrito aos escribas e às funções eclesiásticas.

No mundo urbano-industrial, o domínio das linguagens escritas passaria a ser pressuposto para o estabelecimento de normas, contratos e leis que definiriam os fundamentos e o funcionamento prático das relações sociais e econômicas. A aprendizagem da leitura torna-se o principal objetivo das escolas no século XIX, e ler passa a ser a missão fundamental da educação escolar.

À medida que, do ponto de vista econômico, o mundo urbano-industrial se consolidava, caracterizando mudanças radicais na sociedade, os valores e noções de pertencimento à sociedade também se modificavam.

A escola primária nasce com a função de garantir a formação de cidadãos e com a incumbência de assegurar a manutenção da nova ordem social.

\section{O DESENVOLVIMENTO DA CIÊNCIA E DA TÉCNICA COMO BASE DA SOCIEDADE URBANO-INDUSTRIAL}

Não obstante todas as transformações ocorridas no interior das relações econômicas e sociais da Europa capitalista mercantil e ainda significativamente agrária, havia uma revolução na ordem do pensamento e da produção intelectual que servia de base filosófica para a materialização e a efetivação dessa nova sociedade. Essa revolução recebeu o nome de iluminismo.

Hobsbawm (2014) afirmou que o iluminismo foi a convicção do progresso do conhecimento humano, na racionalidade, na riqueza e no controle sobre a natureza e que daí derivou sua força, primordialmente do evidente progresso da produção, do comércio e da racionalidade econômica e científica que se acreditava estarem associadas a ambos.

Além da racionalidade iluminista, como unidade de pertencimento à sociedade moderna, acrescenta-se a essa construção de pertencimento o caráter nacionalista. 
Trata-se da materialização e consolidação da ordem mundial em Estados Nacionais como forma de pertencimento não apenas à sua dimensão territorial do Estado, ou seja, ao país, mas principalmente ao mundo moderno.

Nesse aspecto, há uma discussão mais aprofundada que deve ser feita, na medida em que dialoga com uma dupla determinação no papel da escola e na escolha das disciplinas que devam fazer parte de seu currículo.

Por um lado, há uma determinação de caráter iluminista que constrói um discurso planetário, uma forma singular e que, cada vez mais, legitima-se como única possibilidade de leitura e entendimento de mundo, qual seja o discurso chamado de "científico".

De outro lado, há um caráter romântico que se configurou no propósito de criação de um sentimento nacionalista. Pertencer a um grupo territorialmente definido e de maneira a naturalizar esse pertencimento faz com que a noção nacionalista passe a ser um dado natural.

Logo, a ascensão do pensamento racionalista inglês e francês, confrontado e acrescido pelo romantismo alemão, influenciou a formação das bases teóricas que sustentaram as transformações radicais na relação da sociedade com o mundo para o desenvolvimento da sociedade urbano-industrial e de caráter nacionalista.

Pode-se assim dizer que foi na fusão entre o romantismo alemão, o iluminismo enciclopédico francês e o tecnicismo inglês que se viu a caracterização do currículo escolar da sociedade urbano-industrial.

Entretanto, há um elo entre essas visões que vai configurar o currículo escolar que passou a ser tradicionalmente conhecido. Nessa questão, busca-se encontrar respostas acerca do motivo de determinadas disciplinas acadêmicas terem se tornado disciplinas escolares e outras, não.

Dessarte, amplia-se a possibilidade de entendimento de como as ciências, a partir do iluminismo e de alguns de seus expoentes, contribuíram para consolidar a ideologia de mundo que marcou todas as etapas posteriores do desenvolvimento econômico, político e cultural da sociedade ocidental e, posteriormente, como tal concepção de mundo se tornou uma demanda para toda a sociedade como forma de pertencimento.

Consequentemente, compreender melhor o significado da escola e do currículo escolar como instituição de inserção dos indivíduos na sociedade vigente nos conduz a refletir com 
maior objetividade sobre os aspectos que conduziram a escolha da Geografia como disciplina a ser adotada na base da formação escolar.

Em virtude das demandas criadas pelo advento das revoluções Industrial e francesa que o homem foi colocado no centro político da caracterização do Estado. O desenvolvimento da tecnologia inglesa, marcado pelo tecnicismo em razão da revolução industrial, e o romantismo alemão constituíram-se num importante elemento de ligação entre a sociedade e o território. Tudo isso diante da necessidade de tais conhecimentos se tornarem de domínio público, disseminados pela educação escolar.

\section{O PAPEL DA REVOLUÇÃO FRANCESA NA DIFUSÃO DA ESCRITA E DO NACIONALISMO}

Embora a invenção da escrita tenha se dado muito antes do contexto da revolução industrial, foi a partir desse momento que sua difusão se tornou fundamental para as transformações ocorridas na sociedade para a consolidação da noção de pertencimento ao modelo urbano-industrial.

Sendo a introdução ao mundo "letrado" um pressuposto para o pertencimento à sociedade urbano-industrial, o domínio da escrita tornava-se uma demanda a ser amplamente difundida. Esse é um dos aspectos que podem apontar para a importância do advento da Revolução Francesa e seus desdobramentos na consolidação dessa nova sociedade.

As implicações políticas e sociais da Revolução Francesa, marcadamente a partir de 1789, significaram para o mundo o fim de uma era. Para Hobsbawm (2014, p. 110), foram as transformações advindas da Revolução Francesa que, na prática, colocaram fim ao feudalismo. "O feudalismo só foi finalmente abolido em 1793".

As revoluções camponesas são movimentos vastos, disformes, anônimos, mas irresistíveis. O que transformou uma epidemia de inquietação camponesa em convulsão irreversível foi a combinação dos levantes das cidades provincianas com uma onda de pânico de massa que se espalhou de forma obscura, mas rapidamente, por grandes regiões do país: o chamado Grande Medo (Grand Peur), de fim de julho e princípio de agosto de 1789. Três semanas após o 14 de julho, a estrutura social do feudalismo rural francês e a máquina estatal da França Real ruíam em pedaços (HOBSBAWM, 2014, p. 110). 
Mais adiante, Hobsbawm (2014) chama a atenção para a importância do advento da Revolução Francesa, no assentido de fazer com que o Estado Moderno passasse a ser Estado Nacional. Assim, caracterizar-se-ia não apenas como "uma área ininterrupta e territorialmente coerente, com fronteiras claramente definidas e governada por uma só autoridade soberana e de acordo com um só sistema fundamental de administração e de leis" (HOBSBAWM, 2014 p. 149), mas também, representado por uma só "nação" ou grupo linguístico.

Não se pode estabelecer uma relação causal entre o advento da Revolução Industrial e da Revolução Francesa - essa seria, por si só, outra tarefa. Deve-se, apenas, considerar os aspectos de um mundo em plena transformação, implicando a configuração de novos padrões sociais, políticos e econômicos.

Para Hobsbawm (2014), a noção nacionalista havia surgido desde a própria Revolução Francesa, justamente pelo aparecimento da ideia de uma "nação revolucionária" e, posteriormente a isso, a partir de 1830, apresentaram-se muitos outros movimentos nacionalistas conscientes, representados pelos movimentos "jovens", tais como "Jovem Itália”, "Jovem Polônia”, "Jovem Alemanha".

Segundo o autor, por si sós, esses movimentos não teriam recebido tanta importância, não fosse o fato de que eles refletiam forças muito poderosas, pelo descontentamento com as condições políticas e econômicas e pela consequente adesão dos pequenos proprietários, baixa nobreza e de uma classe média que estava em construção e tinha como porta-voz, em grande parte, os intelectuais profissionais, ou seja, uma classe educada.

Nesse contexto, via-se que o progresso das escolas e universidades dava a dimensão do nacionalismo, na mesma medida em que as escolas e universidades se tornavam suas defensoras mais conscientes.

Não foi por acaso que na França, após a revolução de 1830, o então Ministro François Guizot instituiu, em 1833, que as escolas francesas fossem públicas e de acesso gratuito a toda a população.

Segundo Hobsbawm (2014, p. 218), “o número de alunos nos liceus estatais franceses duplicou entre 1809 e 1842", apesar de, segundo o mesmo autor, o total de pessoas instruídas ainda ser muito pequeno. Na verdade, conforme o autor, com exceção dos alemães, holandeses, escandinavos, suíços e estadunidenses, não se pode dizer que qualquer outra 
população fosse alfabetizada até o ano de 1840. Sendo assim, verifica-se que a imensa maioria dos europeus (e não europeus) continuava sendo de indivíduos não alfabetizados.

Há um dado importante a ser mencionado diante desse contexto - a adoção das línguas nacionais em alguns países europeus.

Hobsbawm (2014) realça a importância do uso da língua nacional para fins oficiais e para a publicação de jornais e livros. A partir de 1830, Hobsbawm descreve que obras romenas passaram a ser escritas em sua própria língua, em substituição ao grego, assim como, na década seguinte, houve a troca do latim pelo húngaro, para a publicação de obras na Hungria.

Em países onde a língua nacional oficial já existia, no caso da Alemanha, pode-se notar um aumento considerável de publicações na língua oficial (no caso em alemão, em substituição às obras que antes só poderiam ser encontradas em francês).

O que se pode dizer com relação à importância da institucionalização das línguas nacionais oficiais também se pode fazê-lo quanto à demanda pela noção de pertencimento constituído pelo reconhecimento do território nacional.

Nesse sentido, mais adiante, o Estado vai atribuir à escola o papel de consolidar uma ideologia que se constitui (também) por fomentar o pertencimento ao território nacional.

Giolitto (1984) coloca que, no contexto francês das reformas educacionais do século XIX, a fim de cumprir a função de fomentar ideologicamente a unidade nacional francesa, três disciplinas desempenhavam papel fundamental no currículo da escola primária, quais sejam: o ensino da língua materna (o francês), a História e a Geografia.

\section{A INSTITUCIONALIZAÇÃO DA GEOGRAFIA COMO DISCIPLINA ESCOLAR}

Procedendo nessa seção uma análise mais detalhada, ou seja, de maior escala, procurase demonstrar o propósito de institucionalizar a Geografia como disciplina escolar a serviço dessa construção da noção de pertencimento ao mundo urbano-industrial e de caráter nacionalista, como já mencionado.

Embora a Geografia já fizesse parte do rol de ciências acadêmicas, a história de seu surgimento, como uma disciplina pertencente ao currículo escolar, começa primeiro na 
Alemanha e adquire grande notoriedade a ponto de influenciar a França e, posteriormente, os demais países na Europa.

Segundo Moraes (1991), a Geografia moderna originou-se na afirmação dos Estados Nacionais europeus e ganhou grande importância e rápido desenvolvimento especialmente nos países que vivenciaram dificuldades nesse processo. Ele cita a Alemanha como um caso paradigmático, em razão de sua tardia unificação nacional, fazendo desse país o centro teórico da reflexão geográfica ao longo de todo o século XIX.

Para Ribeiro (2009), a eclosão da Geografia como ciência autônoma deve ser vista como um processo histórico caracterizado pelas necessidades políticas (defesa, ordenamento e expansão do território) e ideológicas (criação e reprodução da identidade nacional), provenientes da gestão dos Estados Modernos.

Segundo o referido autor, a centralização dos Estados, a guerra franco-prussiana e o imperialismo são pontos centrais para o entendimento de como a Geografia adquiriu status de disciplina escolar na Alemanha.

É preciso compreender que, na Europa, a manutenção das fronteiras nacionais pode ser explicada, principalmente, pela centralização estatal promovida pelas monarquias absolutistas, ainda no século XVI. Contudo, no caso da Alemanha, tal processo ocorreu tardiamente, efetivando-se apenas a partir do ano de 1871.

Foi com o expansionismo imperialista francês, característico da forma capitalista assumida pela França pós-revolução burguesa de 1789, que Napoleão Bonaparte invade e derrota a Prússia em 1806, promovendo relações tipicamente capitalistas (confederação do Reno): “A soma de uma fraca burguesia, territórios desarticulados, permanência de estruturas feudais e carência de um poder central tornavam a Alemanha presa fácil das ambições de Napoleão Bonaparte” (RIBEIRO, 2009, p. 21).

Contudo, essa modernização econômica não foi suficiente para suprimir definitivamente o poder da aristocracia local que, em 1815, consegue retomar o poder e derrotar Bonaparte.

Para Moraes (1987), se, por um lado, o período napoleônico atuou no sentido da desagregação territorial alemã, por outro, fomentou uma contramarcha romântica e 
nacionalista que visava à construção de uma identidade nacional antagônica à supremacia francesa. Além disso, lançava também o germe das relações capitalistas.

Contudo, evidentemente, existe uma distância enorme entre 1815 e 1871, ano em que a Prússia unifica de fato o território, tornando-se, por fim, a Alemanha como Estado Nacional.

O que se pretende evidenciar é uma declarada intenção de construir uma noção de pertencimento de cunho nacionalista, por parte da crescente classe de intelectuais e que, posteriormente, vai construir mecanismos de massificação desse ideal, tendo a escola como o centro dessa articulação.

Na França, a primeira cátedra em Geografia data de 1809. No entanto, a formação de professores para as escolas primárias e secundárias se efetivou, de maneira mais ampla, apenas nas últimas décadas do século XIX, quando se deu a reforma do ensino, resultante da derrota na guerra franco-prussiana (1870).

Ao longo das décadas seguintes, ficou evidente a preocupação do governo francês de valorizar o ensino de Geografia nas escolas do país (LACOSTE, 1988; MORAES, 2005). A lei de abril de 1867 do Ministro francês Duruy promove a Geografia à lista das disciplinas obrigatórias na escola primária.

Nota-se, portanto, a existência constante da Geografia com as demais disciplinas que compõem as diversas propostas curriculares das escolas primárias e secundárias. Há uma intrínseca relação dessa disciplina com o sistema escolar e, principalmente, com seu papel na construção de pertencimento nacional por meio da identificação dos territórios.

Giolitto (1984), ao apresentar elementos da história do ensino primário francês do século XIX, coloca o ensino primário oferecido a toda a população como fundamentalmente a serviço do Estado, adotando sólida estrutura administrativa e pedagógica.

Logo, tanto a organização pedagógica das escolas quanto os métodos de ensino estavam prescritos e uniformizados em documentos oficiais.

Havia como pressuposto a intenção primeira de elevar o nível de ensino em favor do desenvolvimento econômico do país. Em seguida, a intenção de consolidar as posições das classes dominantes, segundo o autor, incutindo nos alunos um sistema de valores que privilegiasse a ordem das nações, de obediência e de estabilidade, ou seja, munir os cidadãos de um conjunto de referenciais comuns que proporcionassem uma unidade nacional. 
Três disciplinas escolares ocupavam lugar de destaque nesse currículo francês, sendo a Geografia uma das disciplinas formadoras desse tripé.

A Geografia estava assim apresentada como um saber de finalidade essencialmente prática que, segundo Giolitto (1984, p. 189), colocava como "primeira utilidade da geografia a de fazer conhecer e amar a pátria de maneira a incitar os alunos a defendê-la, mais tarde em caso de ataque externo".

Este objetivo do ensino de geografia foi reiterado até sua plenitude após 1870. Para Compayré, a Geografia ensina, "a sua maneira", o patriotismo, fazendo conhecer o território da pátria, as fronteiras que se perderam e aquelas que se conservam, fazendo amar o belo solo da França, seu doce e temperado clima, suas riquezas naturais que fazem dela um país privilegiado (GIOLITTO, 1984, p. 189 - tradução do autor).

Para Giolitto (1984, p. 190), a segunda utilidade da Geografia até o final do século XIX seria a de "conhecer os territórios externos à França", em especial, a Geografia das possessões coloniais, pois isso aguçaria nos alunos a curiosidade e o gosto pelas viagens de exploração e conhecimento - aspectos importantes pelo reconhecimento da grandeza da França e para a manutenção do seu império territorial.

Um conhecimento a serviço do Estado e a constatação de sua importância nesse propósito de incutir o sentimento de pertença não apenas ao país, mas também à ordem mundial que divide o mundo em Estados Nacionais.

\section{CONSIDERAÇÕES FINAIS}

A instituição escolar e, em outra escala de análise, a Geografia, como disciplina escolar, contribuíram para a construção da noção de pertencimento à ordem urbana industrial e nacionalista. Isso se deu por meio da identificação territorial e pela difusão da escrita na forma das descrições das paisagens em textos verbais e não verbais, como iconografias e da linguagem cartográfica.

A instituição escolar, bem como o próprio currículo, revelam seu mecanismo dialético de desempenhar, ao mesmo tempo, um papel conservador, na medida em que assume a tarefa de transmitir um legado cultural para a construção e consolidação dessa noção de 
pertencimento, e revolucionário, por ser em si mesma a síntese das tensões e desdobramentos do controle do Estado na disputa pelos desejos da própria sociedade.

Por conseguinte, a Geografia consolida-se como disciplina dos programas de ensino escolares (francês) e dos sistemas escolares estatais centralizados. Por extensão, ela se tornou também referência para todos os sistemas de ensino estatais concentrados no século XX.

Em virtude de todas as transformações pelas quais a escola, o currículo e, em sua especificidade, o próprio ensino de Geografia vêm passando, há esse debate em pleno vigor na construção e, agora, na consolidação da BNCC brasileira.

Para Lacoste (1988), a Geografia consiste num saber estratégico que pode estar (ou não) a serviço do que chamou de "estado maior", ou seja, voltado para a construção do sentimento de nacionalismo e alienação, elementos fundamentais para as guerras e controle do Estado. Como sugere Moreira (1982), a Geografia serviria, antes de mais nada, para desvendar as máscaras sociais, sendo, portanto, uma linguagem a ser alfabetizada no ambiente escolar com propósitos questionadores e não alienantes.

A Geografia, no ambiente escolar, teria, portanto, o papel de alfabetizar uma "leitura geográfica de mundo", capaz de permitir diversas interpretações e descrições da realidade, conforme a vivência de cada estudante. Como afirmava Freire (1981, p.9), "a leitura de mundo precede a leitura da palavra", colocando a Geografia em consonância com o processo alfabetizador numa perspectiva libertadora e engajada.

Para que se possa ter clareza do papel que se cumpre ao assumir responsabilidade no ensino de determinado saber, acredita-se que seja necessário analisar se tais proposições estão forjadas na configuração dessa BNCC, principalmente aos professores que estarão à frente dessa disciplina em sala de aula.

Diante das contradições a que se impõem um processo de implementação de um currículo oficial para um país com tamanha diversidade e, ainda, num contexto de fortes ataques ao papel ideológico humanizador da escola, devem-se considerar seus aspectos constitutivos para a construção da escola e do ensino de Geografia no ambiente escolar que se pretende para um conhecimento que possa servir a uma condição libertadora e, segundo Torres Santomé (2013), de uso do currículo como possibilidade de construção da justiça social. 


\section{REFERÊNCIAS}

CHIZZOTTI, Antônio; PONCE, Branca Jurema. O currículo e os sistemas de ensino no Brasil. Currículo sem Fronteiras, v. 12, n. 3, p. 25-36, 2012. Disponível em: http://www.educaretransformar.net.br/wp-content/uploads/2017/04/O-curriculo-e-o-ensinono-Brasil.pdf. Acesso em: 13 jun. 2019.

FREIRE, Paulo. Abertura do Congresso Brasileiro de Leitura. Campinas, novembro de 1981.

GIOLITTO, Pierre. Histoire de l'enseignement primaire au XIX $\mathbf{X}^{\mathrm{e}}$ siècle. II, Les méthodes d'enseignement. Paris: Nathan, 1984.

HAMILTON, David. Sobre as origens dos termos classe e curriculum. Revista Teoria e Educação, Porto Alegre, n. 6, p. 33-52, 1992. Disponível em:

https://pt.scribd.com/document/347470194/TEXT0-01-CURR-Origens-Dos-Termos-Classee-Curriculum. Acesso em: 13 jun. 2019.

HOBSBAWM, Eric J. A era das revoluções. 34. ed. Rio de Janeiro: Paz e Terra, 2014.

LACOSTE, Yves. A geografia: isso serve, em primeiro lugar, para fazer a guerra. Campinas: Papirus, 1988.

LURIA, Alexander Romanovich. Diferenças culturais de pensamento. In: VIGOTSKII, Lev Semenovich; LURIA, Alexander Romanovich; LEONTIEV, Alex N. Linguagem, desenvolvimento e aprendizagem. 12. ed. São Paulo: Ícone, 2012. p. 39-58.

MORAES, Antônio Carlos Robert. A gênese da geografia moderna. São Paulo: Hucitec, 1987.

MORAES, Antônio Carlos Robert. Notas sobre identidade nacional e institucionalização da geografia no Brasil. Revista Estudos Históricos, v. 4, n. 8, p. 166-176, 1991. Disponível em: https://bibliotecadigital.fgv.br/ojs/index.php/reh/article/view/2322. Acesso em: 5 abr. 2019.

MORAES, Antônio Carlos Robert. Geografia: pequena história crítica. 20. ed. São Paulo: Annablume, 2005.

MOREIRA, Ruy. A geografia serve para desvendar máscaras sociais. In: MOREIRA, Ruy. (org.). Geografia, teoria e crítica: o saber posto em questão. Petrópolis: Vozes, 1982. p. 3363.

RIBEIRO, Guilherme. Luta pela autonomia e pelo território: geografia e os estados alemão e francês na virada do século XIX ao século XX. Revista Mercator, Fortaleza, v. 8, n. 15, p. 19-28, 2009. Disponível em: http://www.mercator.ufc.br/mercator/article/view/255. Acesso em: 22 maio 2019. 
SANTOS, Douglas. A reinvenção do espaço: diálogos em torno da construção do significado de uma categoria. São Paulo: Unesp, 2002.

THOMPSON, Edward Palmer. Costumes em comum. São Paulo: Companhia das Letras, 1998.

TORRES SANTOMÉ, Jurjo. Currículo escolar e justiça social: o cavalo de Troia da educação. Porto Alegre: Penso, 2013.

\section{NOTAS:}

${ }^{1}$ Trata-se de uma consolidação dos termos na forma de controle, uma vez que, Segundo Hamilton (1992), num artigo dedicado a discutir as origens dos termos "classes" e "currículo", coloca que o conceito de Currículo fora utilizado pela primeira vez no final da Idade Média, ao mesmo tempo que surgiram também as expressões "classes" com a ideia de séries ou seriação.

${ }^{2}$ Tal representação ganha esse nome por dividir o mundo em três continentes, cercados por um oceano, dando uma aparente forma da letra " $\mathrm{T}$ " dentro do círculo que formaria a letra "O".

Recebido em: 29/03/2020

Aprovado em: 22/04/2021 